\title{
Magnesium sulfate enhances non-depolarizing muscle relaxant vecuronium action at adult muscle- type nicotinic acetylcholine receptor in vitro
}

\author{
Hong WANG ${ }^{1,2}$, Qi-sheng $\mathrm{LIANG}^{1}$, Lan-ren $\mathrm{CHENG}^{1}$, Xiao-hong $\mathrm{LI}^{1}$, Wei FU ${ }^{1}$, Wen-tao DAI ${ }^{1}$, Shi-tong $\mathrm{LI}^{2, *}$ \\ ${ }^{1}$ Department of Anesthesiology, the First Affiliated Hospital of Bengbu Medical College, Bengbu 233000, China; ${ }^{2}$ Department of \\ Anesthesiology, First People's Hospital, School of Medicine, Shanghai Jiaotong University, Shanghai 200030, China
}

\begin{abstract}
Aim: To investigate the effect of magnesium sulfate and its interaction with the non-depolarizing muscle relaxant vecuronium at adult muscle-type acetylcholine receptors in vitro.

Methods: Adult muscle-type acetylcholine receptors were expressed in HEK293 cells. Drug-containing solution was applied via a gravity-driven perfusion system. The inward currents were activated by brief application of acetylcholine (ACh), and recorded using whole-cell voltage-clamp technique.

Results: Magnesium sulfate (1-100 mmol/L) inhibited the inward currents induced ACh (10 $\mu \mathrm{mol} / \mathrm{L})$ in a concentration-dependent manner $\left(\mathrm{IC}_{50}=29.2 \mathrm{mmol} / \mathrm{L}\right)$. The inhibition of magnesium sulfate was non-competitive. In contrast, vecuronium produced a potent inhibition on the adult muscle-type acetylcholine receptor $\left(\mathrm{IC}_{50}=8.7 \mathrm{nmol} / \mathrm{L}\right)$ by competitive antagonism. Magnesium sulfate at the concentrations of 1,3 , and $6 \mathrm{mmol} / \mathrm{L}$ markedly enhanced the inhibition of vecuronium (10 $\mathrm{nmol} / \mathrm{L})$ on adult muscle-type acetylcholine receptors.

Conclusion: Clinical enhancement of vecuronium-induced muscle relaxation by magnesium sulfate can be attributed partly to synergism between magnesium sulfate and non-depolarizing muscle relaxants at adult muscle-type acetylcholine receptors.
\end{abstract}

Keywords: magnesium sulfate; non-depolarizing muscle relaxant; vecuronium; adult muscle-type acetylcholine receptor; synergism

Acta Pharmacologica Sinica (2011) 32: 1454-1459; doi: 10.1038/aps.2011.117; published online 10 Oct 2011

\section{Introduction}

Magnesium sulfate $\left(\mathrm{MgSO}_{4}\right)$ has long been used in the treatment of eclampsia or placenta previa, which leads anesthesiologists to more frequent encounters with obstetric patients with hypermagnesemia. The choice of anesthetic techniques for Cesarean sections in such patients is the subject of intense debate $^{[1-3]}$. Although anesthesiologists prefer epidural anesthesia in hypermagnesemic parturients, the risk of coagulopathy or hemodynamic catastrophe often requires anesthesiologists to proceed with urgent general anesthesia.

However, some studies have shown that hypermagnesemia increases the potency of non-depolarizing muscle relaxants, even magnesium, in the range of therapeutic serum concentrations $^{[4-6]}$. Krendal ${ }^{[7]}$ suggested that magnesium sulfate has a pre-synaptic effect by inhibiting acetylcholine release at motor nerve terminals, effects that may be responsible for the inter-

\footnotetext{
* To whom correspondence should be addressed.

E-mail lishitongs@163.com

Received 2011-06-16 Accepted 2011-07-20
}

action with vecuronium. Furthermore, some studies have shown that increasing extracellular magnesium reduces the size of acetylcholine-evoked responses and the single-channel conductance of nicotinic acetylcholine receptors at the mouse end-plate ${ }^{[8-10]}$.

However, no data regarding a combined effect of magnesium sulfate and non-depolarizing muscle relaxants on nicotinic acetylcholine receptors are available in the literature. To evaluate the mechanism of inhibition of magnesium sulfate and non-depolarizing muscle relaxants on nicotinic acetylcholine receptors, we heterologously expressed nicotinic acetylcholine receptors in human embryonic kidney 293 (HEK293) cells and studied the discrete and combined effects of magnesium sulfate with vecuronium, a non-depolarizing muscle relaxant that is often used in general anesthesia.

\section{Materials and methods}

Cell culture and transfection

Expression plasmids [Psp65a, Psp65 $\beta$, Psp65ס, and Pbssk(+) $\varepsilon]$, encoding complementary DNA sequences for the mouse 
muscle nicotinic acetylcholine receptor subunits $(\alpha, \beta, \delta$, and $\varepsilon$, respectively), were provided by the Salk Institute, USA. These coding sequences were subcloned into pcDNA3.1 ${ }^{+}$(Invitrogen Life Technologies, Carlsbad, CA, USA). Human embryonic kidney 293 (HEK293) cells were cultured in Dulbecco's modified Eagle's medium (Invitrogen, Grand Island, NY, USA) supplemented with 10\% calf serum (Invitrogen, Grand Island, NY, USA), 100 units/mL of penicillin, and $100 \mu \mathrm{g} / \mathrm{mL}$ of streptomycin at $37^{\circ} \mathrm{C}$ in a $5 \% \mathrm{CO}_{2}$ incubator. The HEK293 cells were stably transfected with Lipofectamine 2000 according to the manufacturer's protocol (Invitrogen Life Technologies, Carlsbad, CA, USA). After transfection, the positive cell clones were selected with G418, an aminoglycoside related to gentamicin, which is commonly used as a selective agent for eukaryotic cells. The transfected cells were then incubated for $24 \mathrm{~h}$ before the recordings were made.

\section{Electrophysiology}

HEK293 cells were voltage-clamped using the whole-cell patch-clamp technique. Pipettes were pulled from borosilicate glass tubes with a P-97 electrode puller (Sutter Instrument Co, Novato, CA, USA) at a resistance of 2-3 MS. The pipette electrode was filled with the following solution $(\mathrm{mmol} / \mathrm{L})$ : $\mathrm{CsCl}, 140 ; \mathrm{MgCl}_{2}, 0.8$; HEPES-CsOH, 10; EGTA, 0.5; and NaATP, 4 ( $\mathrm{pH} 7.3$ ). The external solution contained the following (mmol/L): $\mathrm{NaCl}, 140 ; \mathrm{KCl}, 2.5 ; \mathrm{CaCl}_{2}, 2 ; \mathrm{MgCl}_{2}, 0.8$; HEPES$\mathrm{NaOH}, 10$; and glucose, 10 (pH 7.3). The $\mathrm{MgSO}_{4}$ solution was composed of the following (mmol/L): $\mathrm{NaCl}, 140 ; \mathrm{KCl}, 2.5$; $\mathrm{MgSO}_{4}, 1,10,30,50$, and 100; HEPES-NaOH, 10; and glucose, 10 ( $\mathrm{pH} 7.3$ ). The cells were voltage-clamped at $-80 \mathrm{mV}$ in the whole-cell configuration, and all of the experiments were performed at room temperature $\left(20-24^{\circ} \mathrm{C}\right)$. The currents were measured with an EPC10 amplifier (HEKA Elektronik, Germany) and PatchMaster software (HEKA Elektronik, Germany), sampled at $20 \mathrm{kHz}$ and stored on a computer.

Acetylcholine and magnesium sulfate were purchased from Sigma (Sigma Chemical Co, St Louis, MO, USA). Vecuronium (NV; Organon, the Netherlands) was obtained in preparations for clinical use, dissolved in the external solution or $\mathrm{MgSO}_{4}$ solution and applied by a gravity-driven perfusion system. The solutions and dilutions for the experimental concentrations were prepared immediately before the experiments. The test solutions, containing either acetylcholine alone or in combination with various concentrations of vecuronium or/ and magnesium sulfate, were applied for $1 \mathrm{~s}$ to the HEK293 cells, and the peak current was then determined. To evaluate the effect of the antagonist on the acetylcholine-elicited current, the solution containing vecuronium or/and magnesium sulfate was perfused on the HEK293 cells for 1 min prior to the application of acetylcholine in the presence of the antagonist. The washout time between each drug application was at least $60 \mathrm{~s}$ to minimize the amount of desensitization throughout the course of the experiment. Current was generated in five HEK293 cells. The control current in response to acetylcholine alone was repeated after the washout of the antagonist. Taking the mean value of these two acetylcholine applications as the average control current, the antagonist response was calculated (percentage inhibition of average control current) using the following equation:

$$
\% \text { Inhibition }=100 \times\left(1-\frac{\text { Current in presence of antagonist }}{\text { Average control current }}\right)
$$

\section{Statistical analysis}

Data analysis was performed offline using Origin 8 (OriginLab, Northampton, MA, USA) and GraphPad Prism 4 (Graphpad Software, Inc, San Diego, CA, USA). Concentrationresponse curves were fitted to the four-parameter logistic equation by non-linear regression analysis, and the $\mathrm{IC}_{50}$ values were determined. The results are expressed as the mean $\pm S D$ or as the $95 \%$ confidence interval (CI). Statistical significance was assessed with paired two-tailed Student's t-tests. A $P<0.05$ was considered statistically significant.

\section{Results}

Acetylcholine at different concentrations was applied for $1 \mathrm{~s}$ to HEK293 cells, which were voltage clamped at $-80 \mathrm{mV}$ and expressed the adult muscle-type acetylcholine receptor. The acetylcholine induced inward currents in a dose-dependent fashion. The data were fitted to the logistic equation, and the acetylcholine concentrations producing $50 \%$ of the maximal response $\left(\mathrm{EC}_{50}\right)$ were $19.1 \mu \mathrm{mol} / \mathrm{L}$ (95\% CI, 7.9-46.1; Figure 1).
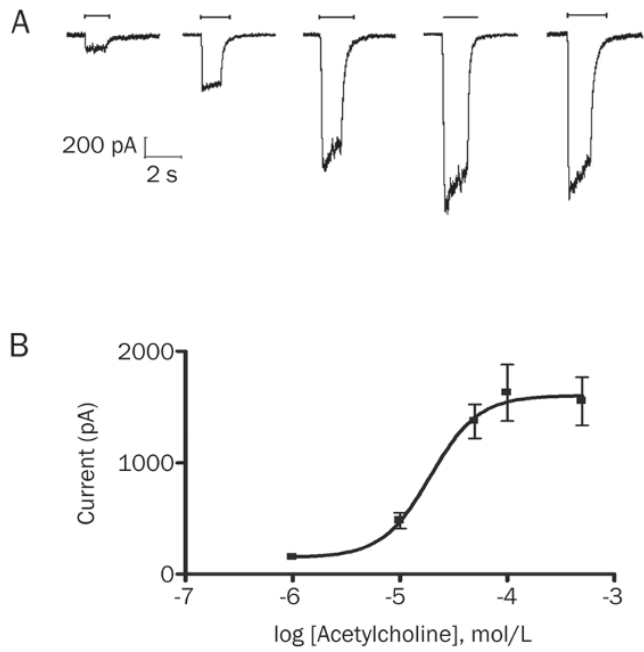

Figure 1. Acetylcholine produces concentration-dependent inward currents in HEK293 cells expressing adult muscle-type acetylcholine receptors. (A) Representative recordings of currents from a single HEK293 cell elicited by 1, 10, 50, 100, and $500 \mu \mathrm{mol} / \mathrm{L}$ acetylcholine (horizontal bars). (B) Concentration-response curve for acetylcholine on adult muscle-type acetylcholine receptor. Data points show the mean \pm SD of 5 HEK293 cells.

\section{Magnesium sulfate inhibited adult muscle-type acetylcholine receptors}

Magnesium sulfate produced a reversible, concentration- 
dependent inhibition of $10 \mu \mathrm{mol} / \mathrm{L}$ acetylcholine-induced currents. Fitting the concentration responses of magnesium sulfate to the Hill equation yielded $\mathrm{IC}_{50}$ values of $29.2 \mathrm{mmol} / \mathrm{L}$ (95\% CI, 14.7-58.0; Figure 2). The inhibitory effect of magnesium sulfate on the adult muscle-type acetylcholine receptors was then studied in more detail. The inward currents evoked from the nicotinic acetylcholine receptors at different acetylcholine concentrations, in the absence and presence of magnesium sulfate, are shown in Figure 3. The peak inward currents under control conditions were dependent on the acetylcholine concentration. Doses of $3 \mathrm{mmol} / \mathrm{L}$ and $30 \mathrm{mmol} / \mathrm{L}$ magnesium sulfate reduced the nicotinic acetylcholine receptormediated inward currents at all of the acetylcholine concentrations studied. Increasing the concentrations of acetylcholine did not overcome the inhibition produced by magnesium sulfate.

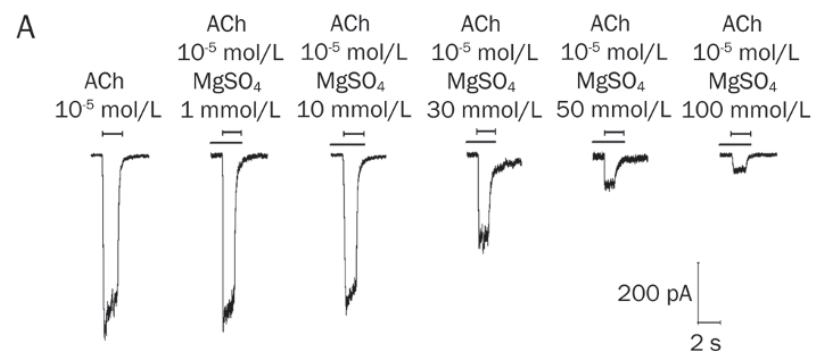

B

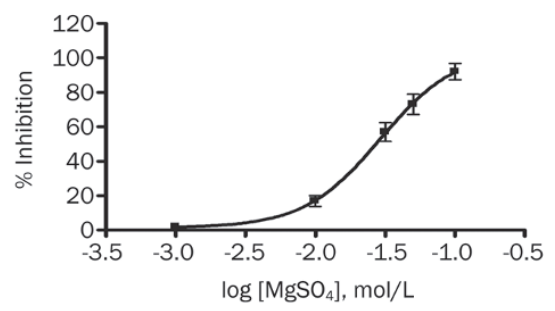

Figure 2. Concentration-dependent effects of magnesium sulphate on adult muscle-type acetylcholine receptors expressed in HEK293 cells. (A) Tracing represent raw currents observed during the application of acetylcholine (ACh; $10 \mu \mathrm{mol} / \mathrm{L}$ for $1 \mathrm{~s}$ ), either alone or in combination with $1,10,30,50$, and $100 \mathrm{mmol} / \mathrm{L}$ magnesium sulphate $\left(\mathrm{MgSO}_{4}\right)$. (B) Concentration-response effect for $\mathrm{MgSO}_{4}$ for inhibition of acetylcholineinduced $(10 \mu \mathrm{mol} / \mathrm{L})$ inward currents mediated by adult muscle-type acetylcholine receptor. Data points show the mean \pm SD of 5 HEK293 cells.

\section{Vecuronium inhibited adult muscle-type acetylcholine receptor}

Vecuronium also produced a potent inhibition of the adult muscle-type acetylcholine receptors. Fitting the concentration responses of vecuronium to the Hill equation yielded $\mathrm{IC}_{50}$ values of $8.7 \mathrm{nmol} / \mathrm{L}$ (95\% CI, 5.5-13.6; Figure 4). Furthermore, at increasing acetylcholine concentrations, there was a significant decrease in the inhibition of the acetylcholine currents produced by $10 \mathrm{nmol} / \mathrm{L}$ vecuronium. At an agonist concentration of $1 \mu \mathrm{mol} / \mathrm{L}$ acetylcholine, $10 \mathrm{nmol} / \mathrm{L}$ vecuronium produced an inhibition of $91 \% \pm 7 \%(n=5)$, whereas at $100 \mu \mathrm{mol} / \mathrm{L}$ acetyl-
A
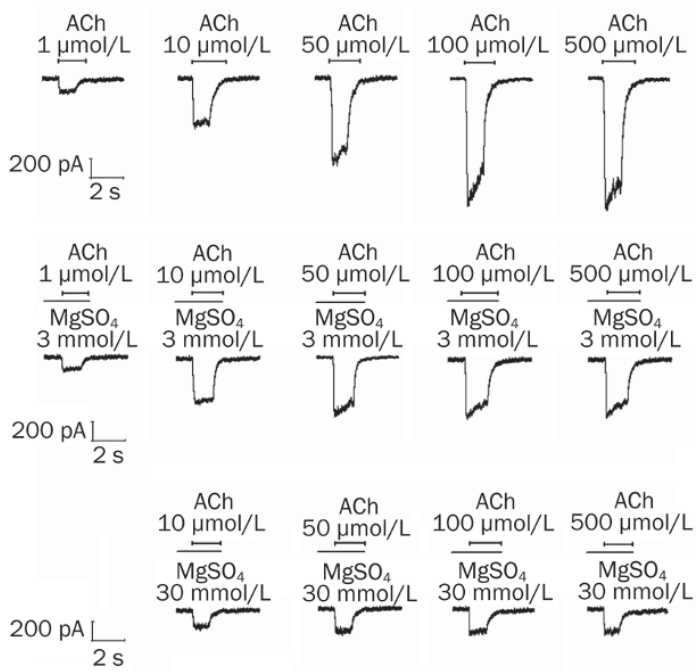

B

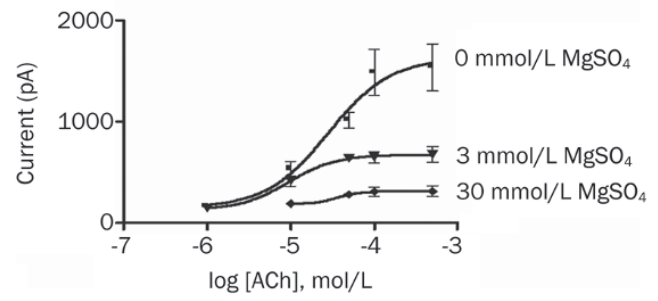

Figure 3. Effect of magnesium sulphate $\left(\mathrm{MgSO}_{4}\right)$ on the concentrationresponse of acetylcholine $(\mathrm{ACh})$ on adult muscle-type acetylcholine receptor. (A) Inward currents evoked by superfusion of 1, 10, 50, 100, and $500 \mu \mathrm{mol} / \mathrm{L}$ ACh alone (as indicated by horizontal bars) during control conditions and co-application of 3 and $30 \mathrm{mmol} / \mathrm{L} \mathrm{MgSO}_{4} . \mathrm{MgSO}_{4}$ was pre-applied for $60 \mathrm{~s}$ before co-application with 1, 10, 50, 100, and 500 $\mu \mathrm{mol} / \mathrm{L} \mathrm{ACh}$. (B) The effect on inward currents mediated by adult muscletype acetylcholine receptor over a range of acetylcholine concentrations in the presence of 0,3 , and $30 \mathrm{mmol} / \mathrm{L}$ magnesium sulphate $\left(\mathrm{MgSO}_{4}\right)$. Data points represent the mean \pm SD of 5 HEK293 cells.

choline, the inhibition was only $9 \% \pm 2 \%(n=5)$, consistent with a competitive inhibition (Figure 5).

Interaction between magnesium sulfate and vecuronium on adult muscle-type acetylcholine receptors

To explore the interaction between magnesium sulfate and vecuronium on the function of the adult muscle-type acetylcholine receptor, we co-applied magnesium sulfate and vecuronium at different concentrations to adult muscle-type acetylcholine receptors. The different concentrations of magnesium sulfate resulted in a strong enhancement of the 10 nmol/L vecuronium-induced inhibition $(P<0.01$; Figure 6). Representative recordings of the raw data for both magnesium sulfate and vecuronium are shown in Figure 7.

\section{Discussion}

It has been shown that the action of non-depolarizing muscle relaxants is significantly prolonged in the presence of therapeutic serum levels of magnesium ${ }^{[1]}$. The mechanism of inter- 
A

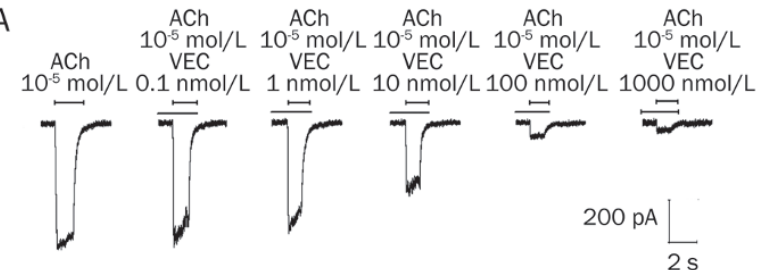

B

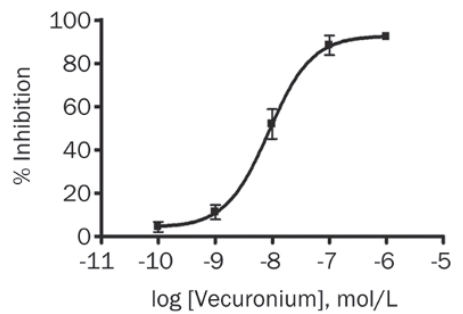

Figure 4. Concentration-dependent effects of vecuronium on adult muscle-type acetylcholine receptors expressed in HEK293 cells. (A) Tracing represent raw currents observed during the application of acetylcholine (ACh; $10 \mu \mathrm{mol} / \mathrm{L}$ for $1 \mathrm{~s}$ ), either alone or in combination with $0.1,1,10$, 100 , and $1000 \mathrm{nmol} / \mathrm{L}$ vecuronium (VEC). (B) Concentration-response effect for vecuronium for inhibition of acetylcholine $(10 \mu \mathrm{mol} / \mathrm{L})$-induced inward currents mediated by adult muscle-type acetylcholine receptor. Data points show the mean \pm SD (error bars) of 5 HEK293 cells.

action for this process was considered to be the pre-synaptic effects of magnesium sulfate; however, this study found that this potentiation of non-depolarizing muscle relaxants by magnesium can be attributed in part to a combined effect on adult muscle-type acetylcholine receptors.

Our study showed that magnesium sulfate produced a concentration-dependent inhibition of the adult muscle-type acetylcholine receptor-mediated inward currents. The $\mathrm{IC}_{50}$ value of magnesium sulfate was $29.2 \mathrm{mmol} / \mathrm{L}$, which far exceeds the serum magnesium concentrations in therapeutic ranges ${ }^{[5,6]}$ and suggested that, in the range of therapeutic concentrations, magnesium alone could not attain a clinically acceptable neuromuscular inhibition. Our findings also showed that the inhibition of the nicotinic acetylcholine receptor function by magnesium sulfate was insurmountable by merely increasing the concentrations of acetylcholine, indicating that magnesium sulfate acts as a non-competitive inhibitor of the adult muscletype acetylcholine receptor. This effect has been ascribed to the high-affinity interactions of divalent cations with negative residues in the channel that decrease the local ion concentration $^{[12]}$.

Consistent with previous studies ${ }^{[13-15]}$, our study also showed that vecuronium potently inhibited the adult muscletype acetylcholine receptor. It is widely recognized that nondepolarizing muscle relaxants inhibit nicotinic acetylcholine receptors by a competitive mechanism ${ }^{[16,17]}$. In this study, an increasing acetylcholine concentration up to $500 \mu \mathrm{mol} / \mathrm{L}$ was able to overcome the inhibition of vecuronium on adult muscle-type acetylcholine receptors, confirming that vecuronium acts in a competitive manner.
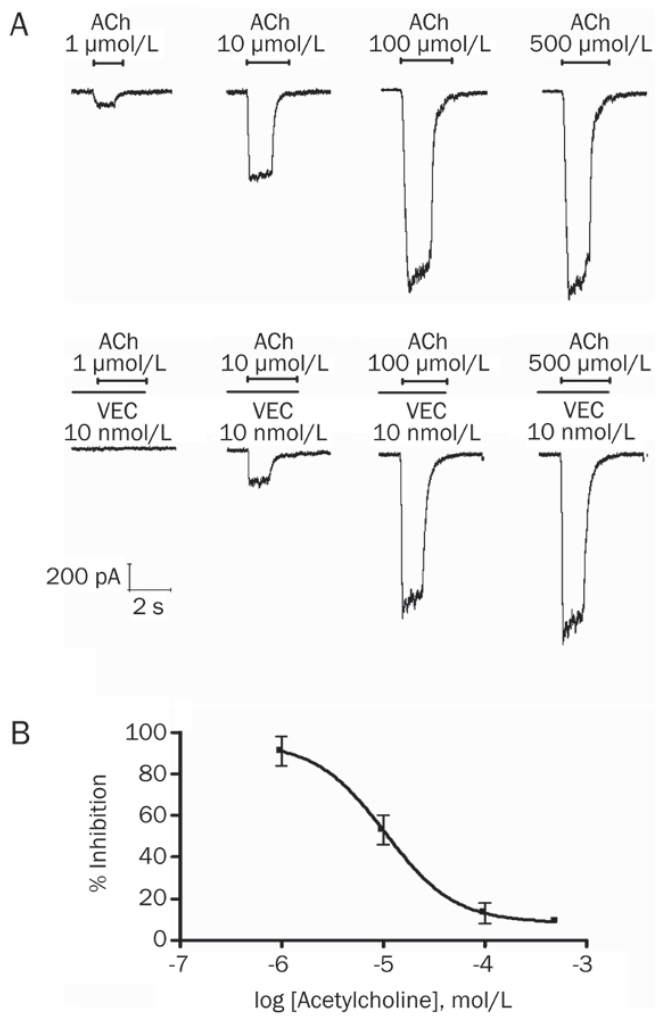

Figure 5. Effect of vecuronium (VEC) on the concentration-response of acetylcholine (ACh) on adult muscle-type acetylcholine receptor. (A) Inward currents evoked by superfusion of $1,10,100$, and $500 \mu \mathrm{mol} / \mathrm{L}$ ACh alone (as indicated by horizontal bars) during control conditions and co-application of $10 \mathrm{nmol} / \mathrm{L}$ vecuronium. Vecuronium was pre-applied for $60 \mathrm{~s}$ before co-application with 1, 10, 100, and $500 \mu \mathrm{mol} / \mathrm{L} \mathrm{ACh}$. (B) The effect on inward currents mediated by adult muscle-type acetylcholine receptor over a range of acetylcholine concentrations in the presence of $10 \mathrm{nmol} / \mathrm{L}$ vecuronium. Data points represent the mean $\pm \mathrm{SD}$ (error bars) of 5 HEK 293 cells.

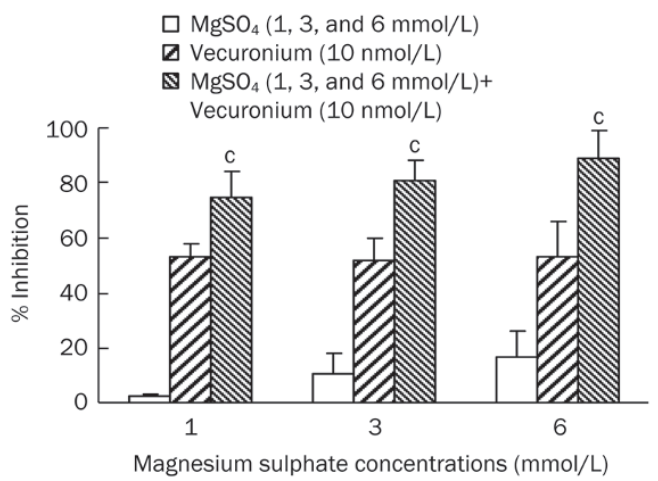

Figure 6. Graphic representation of the enhancement of percentage inhibition of acetylcholine-induced $(10 \mu \mathrm{mol} / \mathrm{L})$ currents with vecuronium and magnesium sulphate $\left(\mathrm{MgSO}_{4}\right)$. ${ }^{\mathrm{c}} P<0.01$ vs vecuronium.

To determine whether magnesium sulfate and vecuronium have an interactive effect, we observed the interaction between 


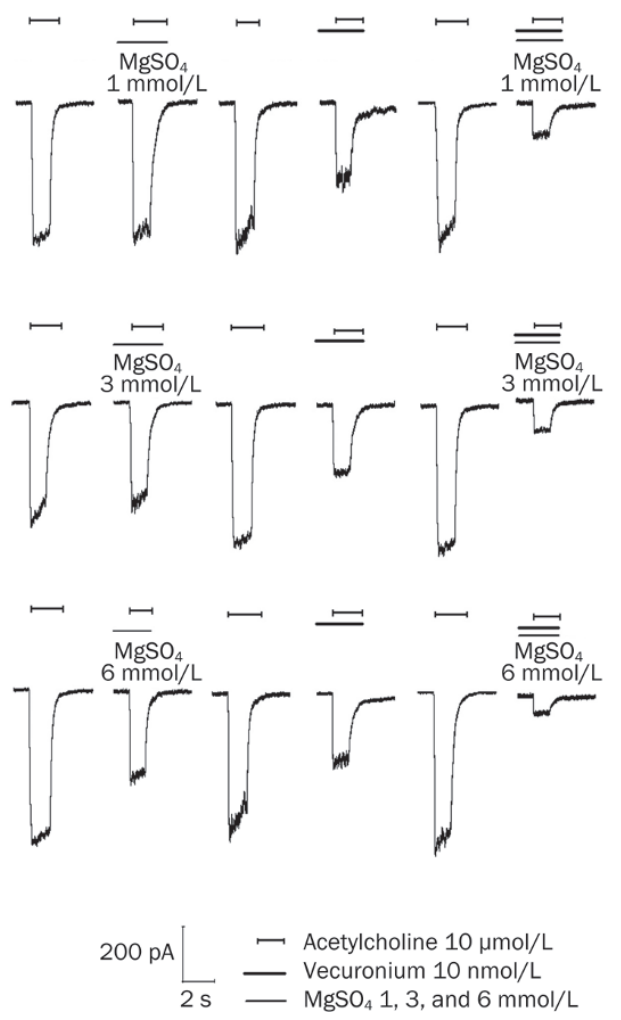

Figure 7. Effect of $10 \mathrm{nmol} / \mathrm{L}$ vecuronium and 1,3 , and $6 \mathrm{mmol} / \mathrm{L}$ magnesium sulphate $\left(\mathrm{MgSO}_{4}\right)$ alone and in combination on acetylcholineinduced $(10 \mu \mathrm{mol} / \mathrm{L})$ inward currents mediated by adult muscle-type acetylcholine receptor. Horizontal bars indicate drug applications. $\mathrm{MgSO}_{4}$, vecuronium, and the combination of both drugs were pre-applied for $60 \mathrm{~s}$ before co-application with $10 \mu \mathrm{mol} / \mathrm{L}$ acetylcholine. After each drug application, a $10 \mu \mathrm{mol} / \mathrm{L}$ acetylcholine-induced inward current was obtained as a control (last control not shown).

three different concentrations of magnesium sulfate $(1,3$, and $6 \mathrm{mmol} / \mathrm{L})$ and vecuronium $(10 \mathrm{nmol} / \mathrm{L})$. Consistent with previous work ${ }^{[4-6]}$, our findings also showed a marked enhancement of the potency of vecuronium by magnesium sulfate with all three of the concentrations tested. Fuchs-Buder et $a l^{[6]}$ reported that an intravenous infusion of magnesium at $40 \mathrm{mg} / \mathrm{kg}$ significantly potentiated the neuromuscular blockage of vecuronium, and plasma magnesium concentrations increased from a baseline concentration of $0.9 \pm 0.06$ to $1.08 \pm 0.07 \mathrm{mmol} / \mathrm{L} 15 \mathrm{~min}$ after the magnesium sulfate infusion $(P<0.05)$. Although this increase in plasma concentration of magnesium in patients pre-treated with magnesium sulfate was statistically significant, the administration of these doses was deemed clinically safe, as no symptoms of muscle weakness were reported by the patients. In addition, Baraka and Yazigi ${ }^{[18]}$ found no clinical or electromyographic signs of muscle weakness, even at slightly higher plasma magnesium concentrations $(1.7-2.5 \mathrm{mmol} / \mathrm{L})$. Thus, in the present study, the potentiation of vecuronium by a $1 \mathrm{mmol} / \mathrm{L}$ magnesium may have more clinical significance.

During the course of our study, we used a concentration of $10 \mu \mathrm{mol} / \mathrm{L}$ of acetylcholine as an agonist. This concentration can ensure sufficient acetylcholine current responses and minimize the desensitization of the nicotinic acetylcholine receptor that resulted from the repetitive application of acetylcholine ${ }^{[13,14]}$. In this study, the HEK293 cells were clamped at $-80 \mathrm{mV}$ because the antagonistic effects of nondepolarizing muscle relaxants are independent of the holding voltages that range from -100 to $-40 \mathrm{mV}^{[13,15,19,20]}$.

\section{Conclusion}

In conclusion, our results demonstrate that the presence of magnesium in the range of therapeutic serum concentrations could significantly intensified the potency of vecuronium on adult muscle-type acetylcholine receptors. These results suggest that the interaction between magnesium and non-depolarizing muscle relaxants on adult muscle-type acetylcholine receptors can partly explain how magnesium enhances a nondepolarizing muscle relaxant-induced neuromuscular blockade.

\section{Acknowledgements}

This work was supported by the National Natural Science Foundation of China (№ 30571796).

\section{Author contribution}

Hong WANG and Shi-tong LI designed the research; Hong WANG and Qi-sheng LIANG performed the research; Xiaohong LI and Lan-ren CHENG analyzed the data; and Hong WANG, Wei FU, and Wen-tao DAI wrote the paper.

\section{Abbreviations}

$\mathrm{MgSO}_{4}$, magnesium sulfate; HEK293, human embryonic kidney 293; nAChR, nicotinic acetylcholine receptor; $\mathrm{IC}_{50}$, halfmaximal response; DMEM, Dulbecco's modified Eagle's medium; ACh, acetylcholine; VEC, vecuronium.

\section{References}

1 Howell P. Spinal anesthesia in severe preclampsia: time for reappraisal or time for caution? Int J Obstet Anesth 1998; 7: 217-9.

2 Aya AG, Mangin R, Vialles NV, Ferrer JM, Robert C, Ripart J, et al. Patients with severe preeclampsia experience less hypotension during spinal anesthesia for elective cesarean delivery than healthy patients: a prospective cohort comparison. Anesth Analg 2003; 97: 867-72.

3 Lipman S, Carvalho B, Brock-Utne J. The demise of general anesthesia in obstetrics revisited: prescription for a cure. Int J Obstet Anesth 2005; 14: 2-4.

4 Ross RM, Backer T. An effect of magnesium on neuromuscular function in parturients. J Clin Anesth 1996; 8: 202-4.

5 Yoshida A, Itoh Y, Nagaya K, Takino K, Sugawara J, Murakami T, et al. Prolonged relaxant effects of vecuronium in patients with deliberate hypermagnesemia: time for caution in cesarean section. J Anesth 2006; 20: 33-5.

6 Fuchs-Buder T, Wilder-Smith $\mathrm{OH}$, Borgeat A, Tassonyi E. Interaction of magnesium sulphate with vecuronium-induced neuromuscular block. Br J Anaesth 1995; 74: 405-9.

7 Krendal DA. Hypermagnesemia and neuromuscular transmission. Semin Neurol 1990; 10: 42-5. 
8 McLarnon JG, Quastel DM. Postsynaptic effects of magnesium and calcium at the mouse neuromuscular junction. J Neurosci 1983; 3: 1626-33.

9 Del Castillo J, Engbaek L. The nature of the neuromuscular block produced by magnesium. J Physiol 1954; 124: 370-84.

10 Grassi F, Degasperi V. Modulation of fetal and adult acetylcholine receptors by $\mathrm{Ca}^{2+}$ and $\mathrm{Mg}^{2+}$ at developing mouse end-plates. Pflugers Arch 2000; 440: 704-9.

11. James MFM. Magnesium in obstetric anesthesia. Int J Obstet Anesth 1988; 7: 115-23.

12 Imoto K, Busch C, Sakmann B, Mishina M, Konno T, Nakai J, et al. Rings of negatively charged amino acids determine the acetylcholine receptor channel conductance. Nature 1998; 335: 645-51.

13 Paul M, Kindler CH, Fokt RM, Dresser MJ, Dipp NC, Yost CS. The potency of new muscle relaxants on recombinant muscle-type acetylcholine receptors. Anesth Analg 2002; 94: 597-603.

14 Wang $\mathrm{H}$, Zhang Y, Li ST. The effect of local anesthetics on the inhibition of adult muscel-type nicotinic acetylcholine receptors by nondepolarizing muscle relaxants. Eur J Pharmacol 2010; 630:
29-33.

15 Garland CM, Foreman RC, Chad JE, Holden-Dye L, Walker RJ. The actions of muscle relaxants at nicotinic acetylcholine receptor isoforms. Eur J Pharmacol 1998; 357: 83-92.

16 Sine SM, Taylor P. Relationship between reversible antagonist occupany and the functional capacity of the acetylcholine receptor. J Biol Chem 1981; 256: 6692-9.

17 Fletcher GH, Steinbach JH. Ability of nondepolarizing neuromuscular blocking drugs to act as partial agonists at fetal and adult mouse muscle nicotinic receptors. Mol Pharmacol 1996; 49: 938-47.

18 Baraka A, Yazigi A. Neuromuscular interaction of magnesium with succinylcholine-vecuronium sequence in the eclamptic parturient. Anesthesiology 1987; 67: 806-8.

19 Wang H, Yang B, Xu YF, Yan T, Li ST. Magnitude differences of resistance to different nondepolarizing muscle relaxants in the denervated mouse skeletal muscle. Acta Pharmacol Sin 2010; 31: 399-404.

20 Wang $\mathrm{H}$, Yang B, Han GW, Li ST. Potency of nondepolarizing muscle relaxants at muscle-type acetylcholine receptors in denervated mouse skeletal muscle. Acta Pharmacol Sin 2010; 31: 1541-6. 